\title{
Destination Strategies to Enhance Secondary and Niche Tourism Products: Literature Review and Case Study
}

\author{
Marco Remondino ${ }^{1}$ \\ ${ }^{1}$ Department of Economics (DIEC), University of Genova, Italy \\ Correspondence: Marco Remondino, Department of Economics (DIEC), University of Genova, Italy. E-mail: \\ marco.remondino@economia.unige.it
}

Received: January 31, 2019

Accepted: March 10, 2019

Online Published: April 18, 2019

doi:10.5539/ijbm.v14n5p52

URL: https://doi.org/10.5539/ijbm.v14n5p52

\begin{abstract}
The topic of this article is enhancing destination competitiveness, with particular interest to entrepreneurial strategies able to valorise secondary and niche attractions. A literature review reveals that, by means of cooperation, local stakeholders could increase success of mass destinations, while promoting the discovery of niche attractions, with a positive impact on the whole territory. Also, the role of DMOs is important, facilitating cooperation among between private and public stakeholders and among private companies. Destination branding strategies could be set, to define the competitive advantages of a territory, leveraging on synergies among primary and secondary attractions. The specific case study of Liguria is proposed and analysed by means of a questionnaire, spread among potential tourists, so to investigate their perceptions about both the capacity of the territory to offer secondary tourism products and the existence and effectiveness of collaborative strategies among local stakeholders. This Italian region has a tourism concentrated during summertime (bathing season), but possesses other specific features, that could differentiate the offer and potentially attract tourists also in other periods. The questionnaire, in fact, reveals that many tourists also like to explore the inland, which should therefore be further promoted. It also emerges than about $9 \%$ of tourists didn't take advantage of secondary tourism products, not being aware of them, while about $46 \%$ believe that secondary attractions could be interesting for tourism, but are not adequately exploited, due to the lack of both strategic cooperation among local businesses and direct promotion.
\end{abstract}

Keywords: destination competitiveness, enhancement strategies, niche tourism, secondary products, Liguria

\section{Introduction}

The theme of the present study is to enhance destination competitiveness (e.g.: Crouch and Ritchie, 1999; Crouch and Ritchie, 2000; Ritchie and Crouch, 2003; Enright and Newton, 2004) and to promote destination branding (e.g. Blain et al., 2005). To be successful, destinations must ensure that the experiences they provide to visitors and their overall attractiveness are on par or better compared to other, alternative, destinations. The attraction of destinations, for tourism, usually depends on the destinations' physical (landscape), environmental (climatic conditions, ecology) and socio-cultural (art, history, religion, food) characteristics or attributes (Jafari, 1982).

At the same time, local and regional cooperation and collaboration is often required, sometimes in the form of coopetition (e.g. Edgell and Haenisch, 1995; Wang and Krakover, 2008; Kylänen, M., and Rusko, 2011), to ensure a quality tourism product that can compete effectively and globally. In particular, these and other researchers highlight the growing links between tourism and cultural activities (e.g.: Van der Ark and Richards, 2006), economic development (e.g.: Kim and Chen, 2006) and joint efforts to bring out lesser-known or niche destinations (e.g. Robinson and Novelli, 2005).

The role of Destination Management Organizations (DMOs) can also be very important, along with the definition and implementation of destination branding strategies (e.g. Blain et al., 2005) able to build up a complex and multifaceted image of a touristic region. Destination management means the set of actions undertaken to amalgamate all the factors of attractiveness and the elements of offer to attract tourist flows, combining in the long run the need to maximize results with the obligation to adopt sustainable behaviour (Presenza, 2008). 
In some tourist destinations there are attractions with strong mass appeal, which allow stakeholders in the area to generate a sustainable business based on them. The example is that of a seaside or mountain resort, where investments have been made for the creation of seaside or ski/excursion tourism. Usually, in these areas, the strategies of companies and DMOs focus on emphasizing existing natural attractions, which are considered as primary tourism products for that territory, while paying little attention to those attractions, which are considered as secondary or complementary, but could potentially enrich the tourists' overall experience.

The initial section of the present work is devoted to a literature review, related to the theme of tourism competitiveness, analysing in particular the strategies to enhance it, starting from the concept of maximizing the benefit for the entire territory, something that could allow greater sustainability as a whole and also a greater profitability of the region at the macro level. This leads to consider the enhancement of secondary tourist attractions as a priority strategy, as well as the creation of tourism niches on territories where other "mass tourism" attractions already exist and prosper. For this purpose, destination branding strategies are of great importance, since they connect different elements, peculiar to the territory (e.g. geography, art, culture, traditions) and bring to the knowledge of potential tourists those secondary and less known aspects that otherwise, except in rare cases, remain unknown.

Subsequently, the work analyses the specific case study of Liguria, a region of Northern Italy. A questionnaire has been set up from the point of view of demand, with the aim of analysing the perceptions of tourists (actual or potential) towards this specific territory.

Liguria has been chosen for this work, since it's a territory where tourism is heavily concentrated during the summer period (bathing season), but it's also a region with many specific features that could potentially attract tourists also in other periods, such as local craftsmanship, food, architecture and, above all, the coexistence of sea and mountains within few square kilometers (Zanini, 2012).

Hence, although mainly known for its sea and coasts, Liguria offers many other potential destinations, mostly known only to locals, which could become secondary attractions, able to enhance the experience of those tourists primarily visiting Liguria for the sea or attract a different type of tourism than purely seaside resorting.

The questionnaire was returned by 204 people. The sample is made up of Italians, distributed throughout the national territory, $65 \%$ female, mainly aged over 18 , with the highest incidence in the following age groups: $18-25$ years $(28.6 \%), 26-35(23.1 \%)$ and $46-55(22.6 \%)$.

The main questions are aimed at understanding what kind of tourism the persons visiting Liguria are interested in, both in the context of their specific local visit and in general (i.e. what they look for, when travelling to other, generic, destinations). The questionnaire investigates about the perceptions of tourists towards secondary tourism products in Liguria. It emerges that these attractions do not appear to have been valued or promoted, by local administrations, from the tourist point of view and, sometimes, they are even physically difficult to discover, being located in small villages, some of which do not even reach 100 inhabitants and are constantly at risk of depopulation. The analysis finally aims to assess whether strategies (business side or based on word-of-mouth) can be used to drive the interest of potential tourists towards secondary attractions in Liguria, currently not exploited.

\section{Competitiveness of Touristic Products}

Primary tourism products are defined (Jafari, 1982) as the main aspects that attract tourists to certain destinations. Diversification, intensification and interconnection between these aspects is fundamental for the competitiveness of touristic destinations and their sustainable development.

Benur and Bramwell (2015) argue that primary tourism products are made up of a complex set of elements. If exploited, this can increase the competitiveness of destinations by offering different experiences and activities. There is greater potential for personalised products that meet the individual needs and interests of tourists and greater flexibility in response to changing tastes and demands in tourism. Diversified tourism products can also be linked through synergetic relationships and cooperation agreements, for example by creating thematic connections and ensuring better coordination and cost sharing, through economies of scale.

In particular, Smith (1994) points out that primary tourism products are composed of elements, interacting with each other, including natural and meteorological characteristics, local services, hospitality, the emotional involvement of the tourist and experiences. It is evident that some of these elements are tangible, while others are immaterial and purely experiential. For the build-up of the primary tourism product, the tourism industry must be able to promote, with suitable strategies, both the physical and objective aspects, as well as the cultural and symbolic meanings that tourists associate with the most intangible ones (Morgan, 2014; Murphy et al., 
2000).

As shown in some researches (e.g. Mo et al., 1993), destination's environment is usually the main factor for tourism decision. Though, also the less tangible aspects of the destination are very relevant: Zeithalm (1988) argues that creating perception of quality and value for travelers is not an easy task, precisely because these experiences tend to be largely complex and intangible.

Primary tourism products are hence complex by themselves, but also other aspects may play an important role in the touristic experience. Russo et al. (2002), in particular, argue that the first determinant of the tourist's choice is the overall quality of the primary tourist products - i.e. the elements that constitute the main reason for the tourist's visit. The second determining factor is the quality of the secondary (or complementary) products. The third factor is the image of the destination.

Both the quality of primary and secondary products and the image of a tourist destination can be improved through targeted and strategic actions by companies and regional government. However, tourism strategies in some cases focus almost exclusively on individual attractions (e.g. Berg et al., 1995; Van der Ark and Richards, 2006), while other elements of competitiveness do not receive adequate attention.

A touristic destination can therefore be considered as a set of individual products and potential experiences, combined on the basis of tourists' needs and expectations. In other words, a tourist destination is a package of tourist facilities and services which is composed of a series of multidimensional attributes ( $\mathrm{Hu}$ and Ritchie, 1993). Hence, it is necessary to understand the links between the product mix of a destination and the perceptions of quality and value that they generate among visitors (Murphy et al., 2000).

A related topic is that of mass vs niche tourism (e.g. Simmons, 1994; Marson, 2011). Mass tourism (Vainikka, 2013) refers to the act of visiting a destination with large amounts of people at one time, while niche tourism (also referred to as "specialty tourism") usually focuses on a specific concept or topic, that could be art, food, sports, or whatever else. Often mass tourism develops towards specific attractions (e.g. the seaside), which, usually, are the ones for which a specific place is known. On the other side, the development of a range of niche products in a destination, rather than a few mass products, could allow tourism to draw on local cultural and environmental specificities, making it relatively more sustainable (Panakera et al., 2011). For example, niche tourism products could act as secondary (complementary) products, when coupled with primary - already well established - mass tourism products.

In fact, it is possible to encourage niche tourism, leveraging on an already developed mass tourism (Lew, 2008). In particular, there can be two main trajectories for the diversification of tourism products. The first is parallel diversification, while the second is integrative diversification (Benur and Bramwell, 2015). Parallel diversification occurs in destinations where basic, different, tourism products attract significantly different customers and hence they are developed, managed and marketed as separate entities, not sharing costs and not finding synergies and complementary links (Bramwell, 2004). Integrative diversification takes place when tourism products are linked and possibly complementary products are combined, with the potential for business cooperation among product suppliers (Nunkoo, 2010).

In some works, relating the competitiveness of the tourist destination (e.g. Mihalič, 2000), the crucial role of DMOs is highlighted, while often the function of service providers at the destination is not the subject of explicit attention (Enright \& Newton, 2005), although, as already pointed out, other authors have stressed the importance of suppliers and the richness of products that contribute to the overall product of the destination.

In particular, the World Tourism Organization defines (2004) the DMO as the organization responsible for the marketing and management of a specific destination. They can be National, Regional or Local Tourism Authorities or Organization, responsible for management and marketing of tourism in their specific area of competence.

Zach (2012) argues that it is mainly DMOs and not individual companies that drive the innovative development of the destination, through fruitful cooperation with these companies and possibly assistance in the development of new specific services, based on possible synergies and tourism demand.

In other works, the importance of cooperation and coordination capacities of the various stakeholders in the tourist destination has been underlined (e.g. Komppula, 2004). By means of cooperation, potential stakeholders located at the tourism destination could increase success of mass destinations, while facilitating the discovery of potential niche destinations and attractions (Bornhorst, 2010), that would not be sufficiently attractive to be a primary mass tourism product by themselves. Weiermair et al. (2010) stress the role of entrepreneurship and innovation as decisive factors in the development of tourism and, along with other researchers (e.g. Beritelli, 
2011; Jesus and Franco, 2016), they state that cooperation is important for the management of all other variables in the tourism system.

In Komppula (2004) a specific survey is conducted on tourism entrepreneurs, and the conclusion is that "entrepreneurs seem to take the responsibility for the development of tourist destination competitiveness, which is contradictory to the mainstream destination competitiveness approach focusing on the pivotal role of DMOs". However, in that same study, entrepreneurs seem to recognise the crucial role of DMOs as facilitators in cooperation between the public and private sectors and, sometimes, also among private companies, partially confirming the studies mentioned above.

Hence, it is possible to speculate than the optimal strategic route to enhance the competitiveness of a destination and to promote secondary - possibly niche - touristic products, is made up of a supervising and facilitating role performed by DMOs, supported by the fundamental cooperation and possibly coopetition at the enterprise level.

Both cooperation at a local level and the role of DMOs are considered as important factors to address tourists towards secondary - less known - attractions. In particular, DMOs can implement destination branding strategies, with the aim to define an "image" for the tourist destination as a whole, comprising both primary and secondary attractions and, above all, amalgamating them in the optimal way to valorise all of them.

In Qu et al., 2011, we read that "destination image (i.e., brand image) is a multi-dimensional construct, influenced by the cognitive, unique, and affective images that collectively affect tourist behaviours". The same study shows that a distinctive image for a destination is directly related to its success for tourism, especially in terms of intention to revisit and in spreading good comments by means of word-of-mouth. Hence, reputation (e.g.: Boella and Remondino, 2009) plays an important role in tourism.

\section{Case Study: Liguria, Italy}

Liguria is a region of north-western Italy, with a resident population of 1,556,981 people (source: ISTAT, as of January 1st, 2018).

Liguria was chosen as a case study for three main reasons. First, because of the leading role played by the region in the Italian context: it has historically been a tourist destination for over a century, just think that on the eve of the Second World War there is a concentration of about 15\% of hotel stays in Italy (Zanini, 2012).

Second, to verify whether the relative uniformity that characterizes the image of this region today, i.e. a "mono-product" touristic area, where the primary attraction is represented by the sea, could be detrimental to the potential exploitation of other potential attractions.

Last but not least, an important motivation is to provide potential new elements to regional development, by the analysis of the touristic demand among potential customers, providing an entrepreneurial point of view that considers strategies at the level of individual companies, synergies among them and institutional measures for the promotion of the territory with particular attention to secondary tourism products.

In the years between the two world wars, in the past century, tourism in Liguria changed radically and progressively became what is still known today. In fact, we are witnessing a change in the seasonality of the flows; previously the typical tourist stay in Liguria was the climate, concentrated in the autumn and winter seasons. The flows interested mainly foreign tourists, while for the Italians the region was not very interesting. Suffice it to say that, until 1929, the tourists in many Ligurian cities were mostly foreign (Zanini, 2012).

Since then, Liguria has been progressively discovered by Italian tourists from neighbouring regions and, at the same time, it has become a seaside tourist destination for the summer period. That was not a contingent phenomenon, but a trend that strengthened over time.

Liguria has great tourist potential, both from the landscape point of view, thanks to its peculiar geographical conformation and mild climate, and from the cultural point of view, thanks to the many small villages in the hinterland, to the food and wine aspects and to the many artistic and architectural features (Zanini, 2012). Despite this, it is also clear, even for those who have never been in this region, that the predominant aspect of the tourist offer is seaside. Moreover, this type of tourism has not required, over the years, great entrepreneurial efforts, thanks mainly to the strategic proximity to other regions (e.g. Piedmont and Lombardy), since the Ligurian structures for beach tourism are often not considered on par with those offered by other regions, which are less convenient to reach (Ugolini, 1996). This makes the present Ligurian tourist offer difficult to adapt to the needs of tourists interested in more varied experiences. With entrepreneurial and institutional efforts, the tourism offer could become integral, multi-product and experiential (Wu et al., 2018). In Liguria, both parallel and integrative diversification could be pursued as entrepreneurial strategies. In particular, being endowed with 
natural attractions (both seaside and mountains), ecotourism could become a revenue generator for the territory (Ayob et al., 2009).

In order to investigate the strategies that the region is currently pursuing, the "Three-year Tourist Plan for Liguria" has been analysed. This document has been implemented by the Regional Agency for Tourism Promotion, with the declared ambition of generating new value in businesses, in the territory and in exchange relations. According to this document, in the last 15 years, there have been profound changes in the way in which tourism is managed in Liguria, especially concerning the structures providing lodging for tourists. In particular structures adapted to agritourisms (holiday farms) and B\&Bs have increased in number. They are usually located in picturesque places, sometimes not in the immediate vicinity of the sea, where people can also taste local products and have cycling and walking tours. As a consequence, this has led to a reduction in the use of traditional hotels, some of which have had to be converted or closed. This indicates a significant perceived change in the needs and habits of the consumer, regarding secondary tourism products in Liguria, with particular emphasis on the hinterland.

The strategy which has attempted to position Liguria as an "all seasons" destination, i.e. not only offering traditional seaside holidays, but also inland activities, culture and gastronomy, seems however to have encountered great difficulties, both in Italy and towards international markets, since it is not supported by a structured product. In particular, there is a limited enhancement and thematicisation of the secondary tourist offer, in particular for sports and "food and wine" tourism products, despite their strong potential.

Even more significantly, from the analysed record it emerges that there has been a reduced synergy between the public and private stakeholders, as well as among private companies, in promoting territorial strategies in terms of cross-tourism policies. In other words, there is little connection between different tourism products and sectors.

\section{Method: A Questionnaire about Tourists' Perceptions}

In order to analyse the touristic attitude of the respondents, with particular attention to the concept of primary and secondary tourism products, a structured questionnaire was spread through the internet, via websites, blogs, social networks, e-mails. The questionnaire was administered to Italians only. This, as it will be also declared in the final part, can be a limitation of the present study and future researches will propose similar questionnaires to international potential tourists.

The questionnaire is structured into three main sections. The first one focuses on socio-demographic variables; along with age, sex, occupation, in this part it is also asked how many trips, on average, are made annually for tourism and how many, among these, are on Italian territory.

The second section is about touristic attitudes in general. As a first question it is asked what is, on average, the main reason for the trips made, among four possibilities (geographical, cultural, gastronomic and sports/ludic attractions). The first category includes, for example, trips made to seaside or mountain resorts in order to mainly take advantage of these attractions, regardless of the specific place and its other characteristics or attributes. The second category includes tourist trips to cities of art, capitals, or places hosting museums and so on. The third category includes itineraries followed with the main purpose of exploring food and wine realities of a particular region, where the tourist will pay particular attention in attending restaurants or fairs that offer dishes, typical products and wines of the area and in visiting wineries and food companies open to the public. Finally, the fourth category includes tourism aimed, as the main motivation, to attend, either as a user or a spectator, sports events (e.g. walking, cycling, skiing) or to visit parks and facilities, such as entertainment resorts or similar.

The second question aims to explore the tourist's interest in secondary tourism products, within a specific territory that is visited mainly for a different (primary) reason. The question asks whether the respondent is, usually, interested in tourism products of a different category than the one previously indicated and, if so, the same categories are proposed again, to investigate which one better fits her interest.

Subsequently, the respondent is invited to reflect on which could be, in his view, the most effective strategy for the promotion of a secondary tourism product. Three possibilities are proposed: direct promotion (for example through advertising in specialized magazines, on the Internet, or directly on the territory), collaboration between stakeholders at the tourist destination (e.g. through cross-promotions or providing specific suggestions), or word-of-mouth (e.g. suggestions from acquaintances or from non-institutional sources, like blogs, forums, or services like Tripadvisor).

As to the third section, the questionnaire follows two distinct paths, determined by whether or not the respondents have been in Liguria for purely touristic reasons. 
If so, it is asked whether Liguria was - on average - the main destination for the trip, or a secondary destination (e.g. intermediate in the context of a trip to a different destination).

It is then asked in which season, mainly, they have been in Liguria for tourism and for which (prevailing) reason, including: seaside tourism, cultural, hiking/landscape/inland, gastronomic, sports. The next question is aimed at understanding whether the tourist has taken advantage of secondary tourism products during his stay in Liguria. If not, it is possible to indicate whether it was due to nescience or, rather, to lack of interest towards the tourist offer. If yes, the same previous categories are proposed again, with the obvious warning to choose a different one from the primary.

Next, it is asked to indicate, regardless of personal touristic experience, what is the prevailing perception about secondary tourism products in Liguria (considering seaside tourism as the primary for mass tourism). In particular, the question is whether, in the respondent's opinion, potential secondary tourism products can be of any interest to the general public. In case they are, it is asked if they are perceived as minor (for objective reasons or, alternatively, for lack of adequate valorisation), if they are indeed significant or if they are perceived as being of greater touristic importance than the seaside tourism products.

Then, with specific reference to Liguria, it is asked which strategies are perceived as the most lacking and the most effective, for the enhancement of secondary attractions, among: direct promotion, cooperation between local businesses and dissemination of information by means of word-of-mouth.

Finally, it is asked whether or not they intend to return to this region for touristic reasons and, in case, which kind of tourism they would be after.

For those who have never been to Liguria for tourism, the main reason for this is requested (among physical distance, perceived high costs or lack of interest in the tourist offer).

Symmetrically to what was asked of the respondents who visited Liguria in the past, it is then asked if they are aware of secondary tourism products on the Ligurian territory (again considering seaside tourism as the primary one for mass tourism) and, if so, if they consider them to be potentially interesting for the general public. The options are the same as those described above.

Last, it is asked if they plan to go to Liguria in the future or not and, if positively replied, for which type of tourism.

\section{Results and Discussion}

The analytical results are depicted in tables A1, A2 and A3. The questionnaire was returned by 204 people. The sample is made up of Italians, distributed throughout the territory, of which $41.2 \%$ female, aged over 18 , with the highest incidence in the following age groups: $36-45$ years $(31.4 \%)$, over $65(25.5 \%), 46-55(15.7 \%)$ and $56-65$ $(13.7 \%)$. The distribution on the national territory is not uniform; most of the respondents live in Piemonte $(52.7 \%)$, followed by Lombardia (17.6\%), which are regions located not far from Liguria. On average, the respondents take about 3 trips for tourism per year, 2 of which are within Italy. The majority of the respondents look for geographical/physical attractions as the main tourism product, followed by cultural attractions. Almost all the respondents (98.4\%) look for secondary tourism products, when travelling to a certain place. Among these, most look for cultural tourism products (37.3\%) followed by geographical attractions (29.7\%) and gastronomic attractions $(25.5 \%)$. The relative majority of respondents $(40,1 \%)$ think that the best general strategy to enhance secondary tourism product would be direct promotion, followed by cooperation among local companies and stakeholders $(32,4 \%)$, while $27.5 \%$ think that the best strategy would be to facilitate word-of-mouth.

Most of the respondents (88.2\%, that's 180 out of 204) have already been in Liguria for tourism, among these an aggregate of $68.9 \%$ go there frequently. This figure is probably determined, as already noted, by the geographical distribution of respondents, which are concentrated, for the major part, within $200 \mathrm{~km}$ from some tourism destination in Liguria. For this specific reason, the discussion focuses more on the perceptions and attitudes of those who have already been in this Region, while the feelings of other respondents will be just briefly mentioned, since that specific sample (24 persons) is not enough to constitute a trend.

The huge majority of the respondents which have been in Liguria for tourism have gone there as the main destination of their trip (93.3\%), while only $6.7 \%$ have visited Liguria as an intermediate stop in the context of a trip towards another destination. Again, this trend can be determined by the fact that most respondents live actually in nearby regions, but can also be a specific indication that Liguria is usually selected as the main destination and not considered for a stop, while travelling to a farther place, just to have a look at local monuments or attractions. 
The subsequent question is revealing about the kind of tourism experience that people look for in Liguria. In fact, $73.3 \%$ of the respondents have been there mainly during summer, and other $15.6 \%$ during spring, i.e. the two seasons when seaside tourism is possible and climate is good. This is partially confirmed by the following question asking for which kind of tourism, mainly, Liguria was selected. Here $61.1 \%$ selected "seaside tourism", but there is an important indication that also excursionism/landscape/Inland is substantial, since it's selected as the main reason by $24.4 \%$ of the respondents. Also, "cultural" tourism has an interesting niche as a main reason for tourism in Liguria, at $8.9 \%$.

The role of excursionism/landscape/Inland strengthens when dealing with secondary tourism products, since $42.2 \%$ of the respondents selected it for this purpose. Considering that this figure is calculated on the total number of the respondents, it has to be adjusted considering that it could be selected only by those who didn't already select is as a primary tourism product. This bring the figure to $55.8 \%$ of people choosing excursionism/landscape/Inland as secondary tourism product, among those who went to Liguria for another, primary reason.

As an aggregate figure, $66.7 \%$ of the respondents chose excursionism/landscape/Inland as their primary or secondary tourism motivation in Liguria, which is an indication about how the natural resources offered in this region, yet different than sea, can constitute an attraction for tourists.

As a comparison, an aggregate total of $72.2 \%$ of the respondents chose seaside tourism as their primary or secondary motivation for visiting Liguria, which is not far from the figure considered above.

Another revealing aspect, emerging from this specific question, is the number of respondents who didn't take advantage of a secondary tourism product, since they were not aware of the opportunities, despite having been on that territory. This figure is high $(8.9 \%)$ meaning that there could be room for improvement in promoting secondary tourism products, even towards tourists that have already been in Liguria. By looking in the individual data, all the respondents that selected this option are among those who indicated seaside tourism as a primary product. Hence, they could have potentially been interested in enriching their experience, but the opportunities were not straightforward for them.

Interestingly, on the other hand, all the replies about the lack of interest in a secondary product, while knowing the opportunities $(4.5 \%$ of the total) come from those who selected primary products different from seaside tourism. This points towards specific niches of tourists, who are not interested at all in seaside tourism in Liguria.

The subsequent question is again a very revealing one, to understand the tourism perception of Liguria. Regardless of the type of tourism that they practiced in Liguria, it is asked if, according to them, secondary tourism products can exist, able to attract mainstream tourism, while considering the seaside tourism as the primary product chosen by the majority of people. The relative majority of respondents $(46.2 \%)$ consider secondary products to actually be potentially interesting for tourism, but not sufficiently exploited and valorised and, hence, they perceive them as marginal and niche products. Only $18.3 \%$ think that they are interesting for mainstream tourism and sufficiently exploited, while $1.7 \%$ don't consider them objectively interesting for mainstream tourism. Last but not least, $13.3 \%$ consider them interesting just for niche/marginal tourism for objective reasons.

Two subsequent questions are then asked about entrepreneurial strategies to enhance and promote secondary tourism products, specifically addressed to Liguria. The figures are interesting and revealing. Most of the respondents consider cooperation among local companies and stakeholders (in the form of direct suggestions from local actors, cross-promotion and synergies) as the most lacking among the proposed options, with regards to Liguria (67.2\%). Even if at a lesser extent, also direct promotion of secondary tourism products is considered as lacking, having been selected by $31.7 \%$. Word-of-mouth, on the contrary, seems not to be felt as lacking, having been selected just by $1.1 \%$.

The fact that cooperation among local stakeholders is considered as lacking in promoting secondary tourism products manifestly contrasts with the fact that, according to the next set of replies, it is considered by respondents as the most effective strategy to reach the proposed goal. In fact, $45.6 \%$ think that the best strategy to promote secondary products would be cooperation among local companies and stakeholders (for example by means of cross-promotions where customers of the primary tourism product are targeted and directed also towards secondary products), followed (at $41.1 \%$ ) by direct promotion on the territory. Just $13.3 \%$ of the respondents believe that word-of-mouth is an effective strategy to promote secondary products in Liguria.

Finally, $91,1 \%$ of the respondents will probably be returning to Liguria for tourism. These returning tourists are 
asked about which kind of primary tourism they will be looking for in Liguria. It is interesting to compare these replies with those given previously about the primary type of tourism they carried out so far in Liguria. In this case, seaside tourism is selected by $56.7 \%$ of the retouring customers (it was $61.1 \%$ in the first place), while excursionism/landscape/Inland as a primary motivation increases to $32.3 \%$ (from $24.4 \%$ ), a further sign that the region should give more and more importance to this kind of touristic attractions on its territory.

While the sample of respondents who have never been to Liguria for tourism is very limited, among these just $16.7 \%$ believe they'll go there in the future (50\% of those mainly for seaside tourism, all of those declaring to not know other opportunities in that place, $25 \%$ mainly to visit inland, $25 \%$ for sport tourism). The main reason for not having been there before is the lack of interest towards the tourist offer, followed by physical distance and costs. Besides, over $37 \%$ of them think that secondary attractions (considering seaside as primary) could exist, yet not adequately exploited and valued.

\section{Conclusion}

A literature review about destination enhancement strategies has been proposed in this paper. The main purpose is that of investigating the possibility of valorise secondary tourism products in those territories where a primary - mass - attraction already exists. This would favour the territory as a whole, while constituting a source of differentiation from the supply side.

Some strategies can be carried on at the local level, where stakeholders, by means of cooperation (and coopetition) could set up strategies and synergies to promote lesser known, or niche, attractions. Also DMOs can act as facilitators in such cooperation, while also promoting destination branding strategies aimed at ensuring that tourists' perception of a destination includes not only the main attraction, but also the potentially wide range of secondary attractions that surround it

Using Liguria as a case study, the paper explores the typical case where a tourism primary product is so dominant as to risk and suppress potential secondary products, at least in terms of promotion. A questionnaire was used to test the perception of tourists towards this Italian region. It emerges that most people visit Liguria for seaside tourism, but many also look for secondary tourism attractions. In particular, inland is attractive for many tourists, both as a primary and a secondary attraction, even if they generally agree that it's not promoted or valorised as it would deserve.

Another important indication is that a relevant number of tourists who have been in Liguria for seaside tourism declare not to know other opportunities on the territory, revealing that destination branding strategies would be overdue. This is further stressed by a large number of respondents who, while knowing and appreciating those secondary opportunities, consider them to be potentially interesting for tourism, yet not sufficiently exploited and promoted. In particular, cooperation among enterprises at a local level is the strategy which is seen as mostly lacking, followed by direct, targeted promotion. Those, along with a coordinating role played by DMOs, should be important strategies to be implemented, in order to revive and valorise the lesser known, yet valuable, secondary attractions in Liguria.

While the results coming from this study are interesting and aligned with the reference literature of this field, confirming how important entrepreneurial strategies can be in promoting secondary tourism products, especially by means of cooperation and coopetition among local stakeholders, it has some inherent limitations.

In particular, the sample of the questionnaire is quite limited, especially for the fact that all the respondents were from Italy and most of them living near Liguria, i.e. the region considered for the case study. Future studies will need a broader and more diverse sample, composed also of people from outside Italy. This would allow to have more respondents who have never been to Liguria for tourism and to capture their perceptions about this region and its secondary tourism products. Future works will also present a simulation framework (Remondino, 2005), based on the results coming from the questionnaire.

\section{References}

Ayob, M. Z., Saman, F. M., Hussin, Z. H., \& Jusoff, K. (2009). Tourists' satisfaction on Kilim river mangrove forest ecotourism services. International Journal of Business and Management, 4(7), 76. https://doi.org/10.5539/ijbm.v4n7p76

Benur, A. M., \& Bramwell, B. (2015). Tourism product development and product diversification in destinations. Tourism Management, 50, 213-224.

Berg, L. D., Borg, J., \& Meer, J. V. (1995). Urban tourism: performance and strategies in eight European cities. Avebury. 
Beritelli, P. (2011). Cooperation among prominent actors in a tourist destination. Annals of Tourism Research, $38(2), 607-629$.

Blain, C., Levy, S. E., \& Ritchie, J. B. (2005). Destination branding: Insights and practices from destination management organizations. Journal of travel research, 43(4), 328-338.

Boella, G., \& Remondino, M. (2009). Collaboration and Human Factor as Drivers for Reputation System Effectiveness. In International Conference on Web Information Systems and Technologies (pp. 3-16). Springer, Berlin, Heidelberg.

Bornhorst, T., Ritchie, J. B., \& Sheehan, L. (2010). Determinants of tourism success for DMOs \& destinations: An empirical examination of stakeholders' perspectives. Tourism management, 31(5), 572-589.

Bramwell, B. (2004). Mass tourism, diversification and sustainability in Southern Europe's coastal regions. Coastal mass tourism: Diversification and sustainable development in Southern Europe, 12, 1.

Crouch, G. I., \& Ritchie, J. B. (1999). Tourism, competitiveness, and societal prosperity. Journal of business research, 44(3), 137-152.

Crouch, G. I., \& Ritchie, J. B. (2000). The competitive destination: A sustainability perspective. Tourism management, 21(1), 1-7.

Edgell, D. L., \& Haenisch, R. T. (1995). Coopetition: Global tourism beyond the millennium; charting the course for education, government, and commerce. Internat. Policy Publ.

Enright, M. J., \& Newton, J. (2004). Tourism destination competitiveness: a quantitative approach. Tourism management, 25(6), 777-788.

Enright, M. J., \& Newton, J. (2005). Determinants of tourism destination competitiveness in Asia Pacific: Comprehensiveness and universality. Journal of Travel Research, 43(4), 339-350.

Hu, Y., \& Ritchie, J. B. (1993). Measuring destination attractiveness: A contextual approach. Journal of travel research, 32(2), 25-34.

Jafari, J. (1982). The tourism market basket of goods and services: the components and nature of tourism. The tourism market basket of goods and services: the components and nature of tourism, 1-12.

Jesus, C., \& Franco, M. (2016). Cooperation networks in tourism: A study of hotels and rural tourism establishments in an inland region of Portugal. Journal of Hospitality and Tourism Management, 29, 165-175.

Kim, H. J., \& Chen, M. H. (2006). Tourism expansion and economic development: The case of Taiwan. Tourism management, 27(5), 925-933.

Kim, N., \& Wicks, B. E. (2010). Rethinking tourism cluster development models for global competitiveness. Presented at International CHRIE Conference-Refereed Track. Paper 28.

Komppula, R. (2004). Commitment to co-operation-a key to effective networking in tourism industry. The future of small and medium sized enterprises in tourism, 163-178.

Kylänen, M., \& Rusko, R. (2011). Unintentional coopetition in the service industries: The case of Pyhä-Luosto tourism destination in the Finnish Lapland. European Management Journal, 29(3), 193-205.

Lew, A. A. (2008). Long tail tourism: New geographies for marketing niche tourism products. Journal of Travel \& Tourism Marketing, 25(3-4), 409-419.

Marson, D. (2011). From mass tourism to niche tourism. Research Themes for Tourism, 1-11.

Mihalič, T. (2000). Environmental management of a tourist destination: A factor of tourism competitiveness. Tourism management, 21(1), 65-78.

Mo, C. M., Howard, D. R., \& Havitz, M. E. (1993). Testing an international tourist role typology. Annals of tourism research, 20(2), 319-335.

Murphy, P., Pritchard, M. P., \& Smith, B. (2000). The destination product and its impact on traveller perceptions. Tourism management, 21(1), 43-52.

Nunkoo, R., \& Ramkissoon, H. (2010). Modeling community support for a proposed integrated resort project. Journal of Sustainable Tourism, 18(2), 257-277.

Panakera, C., Willson, G. B., Ryan, C., \& Liu, G. (2011). Considerations for sustainable tourism development in developing countries: perspectives from the South Pacific. 
Presenza, A. (2008). Destination Management Organization. Ruolo, organizzazione ed indicatori di performance (Vol. 5). FrancoAngeli.

Qu, H., Kim, L. H., \& Im, H. H. (2011). A model of destination branding: Integrating the concepts of the branding and destination image. Tourism management, 32(3), 465-476.

Remondino, M. (2005). Reactive and deliberative agents applied to simulation of socio-economical and biological systems. International Journal of Simulation, 6(12-13), 11-25.

Ritchie, J. B., \& Crouch, G. I. (2003). The competitive destination: A sustainable tourism perspective. Cabi Publishing, Oxon, UK.

Robinson, M., \& Novelli, M. (2005). Niche tourism: an introduction. Niche tourism: Contemporary issues, trends and cases, 1-11.

Russo, A. P., \& Van Der Borg, J. (2002). Planning considerations for cultural tourism: a case study of four European cities. Tourism management, 23(6), 631-637.

Simmons, D. G. (1994). Tourism Alternatives: Potentials and Problems in the Development of Tourism. New Zealand Geographer, 50(2), 57-58.

Smith, S. L. (1994). The tourism product. Annals of tourism research, 21(3), 582-595.

Trunfio, M., Petruzzellis, L., \& Nigro, C. (2006). Tour operators and alternative tourism in Italy: Exploiting niche markets to increase international competitiveness. International Journal of Contemporary Hospitality Management, 18(5), 426-438.

Ugolini, G. M. (1996). Turismo, valori ambientali e organizzazione del territorio: il caso della Liguria.

Vainikka, V. (2013). Rethinking mass tourism. Tourist Studies, 13(3), 268-286.

Van der Ark, L. A., \& Richards, G. (2006). Attractiveness of cultural activities in European cities: A latent class approach. Tourism Management, 27(6), 1408-1413.

Wang, Y., \& Krakover, S. (2008). Destination marketing: competition, cooperation or coopetition?. International Journal of Contemporary Hospitality Management, 20(2), 126-141.

Weiermair, K., Keller, P., Pechlaner, H., \& Go, F. M. (Eds.). (2010). Innovation and entrepreneurship: Strategies and processes for success in tourism. Erich Schmidt Verlag GmbH \& Co KG.

Wu, H. C., Cheng, C. C., \& Ai, C. H. (2018). A study of experiential quality, experiential value, trust, corporate reputation, experiential satisfaction and behavioral intentions for cruise tourists: The case of Hong Kong. Tourism Management, 66, 200-220.

Zach, F. (2012). Partners and innovation in American destination marketing organizations. Journal of Travel Research, 51(4), 412-425.

Zanini, A. (2012). Un secolo di turismo in Liguria: dinamiche, percorsi, attori (Vol. 195). FrancoAngeli.

\section{Appendix A}

In the following, the extensive results from the questionnaire are shown. In table A1, demographics of respondents and general touristic attitudes are exposed. In table A2, results about tourism experience in Liguria are depicted. Last, in table A3, the results coming from the respondents who have never been in Liguria for tourism.

Table A1. Demographics of respondents and general touristic attitudes

\begin{tabular}{lc}
\hline Section 1 - Demographics of respondents and general touristic attitudes & \\
\hline Age & $3,9 \%$ \\
$18-25$ & $9,8 \%$ \\
$26-35$ & $31,4 \%$ \\
$36-45$ & $15,7 \%$ \\
$46-55$ & $13,7 \%$ \\
$56-65$ & $25,5 \%$ \\
$>65$ & \\
Gender & \\
\hline
\end{tabular}




\begin{tabular}{|c|c|}
\hline Female & $41,2 \%$ \\
\hline Male & $58,8 \%$ \\
\hline \multicolumn{2}{|l|}{ Region of residence } \\
\hline Piemonte & $52,7 \%$ \\
\hline Lombardia & $17,6 \%$ \\
\hline Emilia & $8,8 \%$ \\
\hline Lazio & $4,9 \%$ \\
\hline Toscana & $3,1 \%$ \\
\hline Marche & $2,3 \%$ \\
\hline Abruzzo & $2,1 \%$ \\
\hline Other regions (less than $2 \%$ each) & $8,5 \%$ \\
\hline \multicolumn{2}{|l|}{ Job position } \\
\hline Retired from work & $27,5 \%$ \\
\hline Freelancer & $13,7 \%$ \\
\hline Entrepreneur & $4,9 \%$ \\
\hline Manager/Director & $1,5 \%$ \\
\hline Employee & $46 \%$ \\
\hline Workman or similar & $3,9 \%$ \\
\hline Student & $2,9 \%$ \\
\hline How many trips (for tourism) do you take on average per year? & 3,18 \\
\hline How many of these, on average, are in Italy? & 2,1 \\
\hline \multicolumn{2}{|l|}{ More frequently, what is the primary reason for your tourism? } \\
\hline Geographical attractions (e.g. seaside tourism, mountain tourism) & $53,8 \%$ \\
\hline Cultural attractions (e.g. museums/art/architecture or cities) & $35,3 \%$ \\
\hline Gastronomic attractions & $1,1 \%$ \\
\hline Sports/ludic attractions (e.g. tournaments, amusement parks) & $9,8 \%$ \\
\hline
\end{tabular}

Do you usually look for secondary touristic experiences in addition to the primary reason, in the same place? If yes, choose one that differs from the primary one expressed above.

No

Geographical attractions (e.g. seaside tourism, mountain tourism) $\quad 29,7 \%$

Cultural attractions (e.g. museums/art/architecture or cities) $37,3 \%$

Gastronomic attractions $\quad 25,5 \%$

Sports/ludic attractions (e.g. tournaments, amusement parks) $\quad 5,9 \%$

In general, what do you think is the most important factor, for the enhancement and diffusion of a secondary tourism product?

Direct promotion of such experiences (e.g. advertising in magazines, billboards, internet) $40,1 \%$

Cooperation among local companies and stakeholders (e.g. direct suggestions from local actors, cross-promotions) $32,4 \%$

Dissemination of information and news by word-of-mouth (e.g. advice from friends, information from non-institutional sources: $27,5 \%$

blogs, forums...)

Have you been to Liguria for tourism?

Yes

Table A2. Tourism experience in Liguria

Section 2 - Tourism experience in Liguria

How often do you visit Liguria for tourism?

I've been there only once

$6,7 \%$

$24,4 \%$

Rarely (on average every 3-4 years or less)

$20 \%$

With good frequency (on average once every 1-2 years)

$48,9 \%$

Often (more than one time per year)

context of a trip to

Was Liguria, on aver
another destination)?

Yes

$93,3 \%$

No

$6,7 \%$

In which season of the year, on average, did you go to Liguria for tourism? 


\begin{tabular}{lc}
\hline Summer & $73,3 \%$ \\
Winter & $6,7 \%$ \\
Spring & $15,6 \%$ \\
Autumn & $4,4 \%$ \\
For which kind of tourism (mainly) did you visit Liguria? & $61,1 \%$ \\
Seaside & $8,9 \%$ \\
Cultural & $24,4 \%$ \\
Excursionism/landscape/Inland & $1,2 \%$ \\
Gastronomic & $4,4 \%$
\end{tabular}

In addition to the reason mentioned above (primary), was your tourist experience in Liguria significantly enriched by secondary experiences? If so, what was the most significant? (different from the one indicated as primary)

No, because I didn't know the opportunities $\quad 8,9 \%$

No, I knew the opportunities, but I was NOT interested $\quad 4,5 \%$

Seaside $11,1 \%$

Cultural $6,7 \%$

Excursionism/landscape/Inland $\quad 42,2 \%$

Gastronomic $24, \%$

Sports $2,2 \%$

Whatever type of tourism you practised, considering that the majority of tourists in Liguria consider seaside tourism as their primary aim, do you think that the secondary attractions offered in the area could be of any interest for the public?

I don't know them. $9,4 \%$

No (I know them but I do not consider them potentially interesting for tourism) $\quad 1,7 \%$

Yes, but only as marginal, for objective reasons. $13,3 \%$

Yes, but only as marginal, because not adequately exploited and valued $\quad 46,2 \%$

Yes, they are significant and adequately exploited and valued $18,3 \%$

Yes, potentially even more important than seaside tourism $11,1 \%$

Which one, among these, do you perceive as the most lacking, as a strategy to promote secondary tourism products in Liguria?

Direct promotion of such experiences (e.g. advertising in magazines, billboards, internet) $31,7 \%$

Cooperation among local companies and stakeholders (e.g. direct suggestions from local actors, cross-promotion) $\quad 67,2 \%$

Dissemination of information and news by word-of-mouth (e.g. ad-vice from friends, information from $1,1 \%$ non-institutional sources: blogs, forums...)

Specifically, which one of these strategies do you consider as the most effective to enhance secondary tourism products in Liguria?

Direct promotion of such experiences

$41,1 \%$

Cooperation among local companies and stakeholders

Dissemination of information and news by word-of-mouth $\quad 13,3 \%$

Will you return to Liguria for tourism?

Probably Yes $\quad 91,1 \%$

Probably No $8,9 \%$

If yes, for what type of tourism (mainly) will you travel to Liguria in the future?

Seaside $56,7 \%$

Cultural $2,4 \%$

Excursionism/landscape/Inland $\quad 32,3 \%$

Gastronomic $\quad 4,3 \%$

Sports $\quad 4,3 \%$

Apart for the primary reason, do you plan on takin advantage also of secondary tourism products? If so, which one, mainly?

No, because I don't know the opportunities $\quad 9,1 \%$

No, I know the opportunities, but I'm NOT interested $\quad 4,3 \%$

Seaside $\quad 12,8 \%$

Cultural $21,4 \%$

Excursionism/landscape/Inland $\quad 37 \%$

Gastronomic $13,4 \%$

Sports $2,40 \%$ 
Table A3. Never been in Liguria for tourism

Section 3 - Never been in Liguria for tourism

What is the main reason for never having been there?

Physical distance

Costs perceived as high

Lack of interest in the tourist offer

Given that the majority of tourists in Liguria consider seaside tourism to be the primary tourism product, do you believe that secondary attractions offered in the area could be of interest to the general public?

I don't know them.

No (I know them but I do not consider them potentially interesting for tourism)

Yes, but only as marginal, for objective reasons.

Yes, but only as marginal, because not adequately exploited and valued

Yes, they are significant and adequately exploited and valued

Yes, potentially even more important than beach tourism

Do you plan to travel to Liguria for tourism in the future?

Yes, probably

Probably not

If yes, for what type of tourism (mainly) will you travel to Liguria in the future?

Seaside

Cultural

Excursionism/landscape/Inland

Apart for the primary reason, do you plan on takin advantage also of secondary tourism products? If so, which one, mainly?

No, because I don't know the opportunities

No, I know the opportunities, but I'm NOT interested $\quad 0 \%$

Seaside $25 \%$

Cultural $0 \%$

Excursionism/landscape/Inland $\quad 25 \%$

Gastronomic $\quad 0 \%$

Sports

$2,10 \%$

\section{Copyrights}

Copyright for this article is retained by the author(s), with first publication rights granted to the journal.

This is an open-access article distributed under the terms and conditions of the Creative Commons Attribution license (http://creativecommons.org/licenses/by/4.0/). 